\title{
Milliliter per Minute per Millimeters of Mercury per Liter
}

National Cancer Institute

\section{Source}

National Cancer Institute. Milliliter per Minute per Millimeters of Mercury per Liter. NCI

Thesaurus. Code C67418.

A unit for measuring a pulmonary diffusing capacity adjusted for lung volume expressed in units of gas flow rate (in milliliters per minute) per a unit of pressure (in torrs) per one liter. 